\title{
A CONTRIBUIÇÃO DO PIBID NA FORMAÇÃO INICIAL E CONTINUADA DE PROFESSORES DE FÍSICA PARA SUA CONSTITUIÇÃO PROFISSIONAL
}

\author{
Eduardo de Almeida ${ }^{1}$ \\ Eliane Gonçalves dos Santos ${ }^{2}$ \\ Rosemar Ayres dos Santos ${ }^{3}$ \\ Viviane Scheibel de Almeida ${ }^{4}$
}

\section{RESUMO}

Este capítulo apresenta ações e experiências que o Programa Institucional de Bolsas de Iniciação à Docência (PIBID), Subprojeto Física vem vivenciando desde agosto de 2018, nas cidades de

1 Doutor em Física. Professor adjunto da Universidade Federal da Fronteira Sul (UFFS), coordenador de área do Subprojeto de Física (Campus Realeza/PR) do PIBID-UFFS. Contato: eduardo.almeida@uffs.edu.br

2 Doutora em Educação nas Ciências. Professora adjunta da Universidade Federal da Fronteira Sul (UFFS), colaboradora do Subprojeto Física (Campus Cerro Largo/RS). Contato: santoselianegoncalves@gmail.com

3 Doutora em Educação. Professora adjunta da Universidade Federal da Fronteira Sul (UFFS), coordenadora de área do Subprojeto de Física (Campus Cerro Largo/RS) do PIBID-UFFS. Contato: roseayres07@gmail.com

4 Doutora em Física. Professora adjunta da Universidade Federal da Fronteira Sul (UFFS), colaboradora do Subprojeto de Física (Campus Realeza/PR) do PIBID-UFFS. Contato: viviane.scheibel@uffs.edu.br 
Realeza/PR e Cerro Largo/RS e em suas imediações, contribuindo para o desenvolvimento da alfabetização científico-tecnológica dos professores em formação inicial. Dentre as atividades desenvolvidas, destaca que o trabalho está alinhado às premissas da Base Nacional Comum Curricular (BNCC) por meio da produção de materiais didáticos, desenvolvimento de atividades práticas, incentivo ao uso de recursos tecnológicos, fomento a aprendizagem investigativa, problematizadora e autônoma e, também, promovendo formação continuada de professores das escolas e professores formadores da Universidade Federal da Fronteira Sul (UFFS).

Palavras-chave: Ensino de Física. Experimentação. Formação. Investigação na escola. Problematização.

\section{O CONTEXTO FORMATIVO}

As escolas de Educação Básica, em especial, as da rede pública de ensino, são constituídas de indivíduos com interesses e realidades diversas, entre os quais, alguns já trabalham e almejam somente finalizar o Ensino Médio, outros provenientes de regiões rurais auxiliam suas famílias nas tarefas do dia a dia da propriedade, há, também, os que querem fazer um curso superior e os que ainda não sabem o que querem.

Nesse universo de interesses, o modelo de aulas expositivas e muito teóricas tornam-se a cada dia mais desmotivantes para a maioria dos estudantes. Assim, muitas vezes, as aulas de Física costumam dar um tratamento matemático excessivo, descontextualizado do cotidiano vivido pelo estudante e centrado na resolução teórica de exercícios em situações idealizadas.

Dessa forma, faz-se necessário que pensemos novas formas de ensinar Física, as quais sejam mais atraentes e que façam algum sentido no cotidiano desse estudante. Mas como fazer uma aula de Física ter sentido para essa diversidade que é a escola? Quais habilidades e competências a escola deve trabalhar em um 
grupo tão heterogêneo? Como elaborar aulas a fim de suprir as expectativas de todos os estudantes? Esses são alguns dos desafios que a escola contemporânea presencia em uma realidade na qual as tecnologias vêm tomando a atenção dos estudantes em sala de aula. Seria a educação problematizadora uma sinalização?

Na verdade, nenhum pensador, como nenhum cientista, elaborou seu pensamento ou sistematizou seu saber científico sem ter sido problematizado, desafiado. Embora isso não signifique que todo homem desafiado se torne filosofo ou cientista, significa, sim, que o desafio é fundamental à constituição do saber. (FREIRE, 2002, p. 54).

Nessa perspectiva, quando consideramos o contexto da formação inicial do professor, compreendendo a necessidade de melhor formar esse sujeito para sua iniciação à docência para viver essa realidade posta, necessitamos ponderar duas questões fundamentais, identificadas por Nardi e Cortela (2015, p. 36): "como melhorar a formação de professores de Física e/ou o imaginário sobre o licenciando de Física nesse contexto? Há interesse dos pares em discutir questões como essas, ou modificar os panoramas encontrados?"

Com essas problemáticas em mente, tanto relativas a questões da escola básica, quanto da formação inicial e continuada de professores de Física, ponderamos que o projeto do Programa Institucional de Bolsas de Iniciação à Docência (PIBID), da Universidade Federal da Fronteira Sul (UFFS) e, mais especificamente, o subprojeto Física - com dois núcleos: um do Campus Realeza/PR e outro Campus Cerro Largo/RS - pode contribuir para uma melhor formação inicial e continuada do professor e, também, para promover motivação para o estudante da Educação Básica querer aprender Física, condição necessária para o aprender, como nos refere Freire (2009), despertar a curiosidade epistemológica. 
O subprojeto visa a contribuir para o desenvolvimento da alfabetização científico-tecnológica dos professores em formação inicial com a realização de práticas educativas e outras atividades didático-pedagógicas em diferentes espaços de formação, entre os quais, a universidade e a escola, sempre com acompanhamento, seja do professor coordenador de área, seja do professor supervisor.

Desse modo, entendemos que com a participação no subprojeto Física, os licenciandos, professores em formação inicial, estarão tendo maior incentivo na sua formação para a atuação na Educação Básica, conhecendo o campo de atividade profissional. Essa participação contribui inclusive para quando na oportunidade dos estágios supervisionados, esses já estarem mais bem preparados para realizá-lo, pelo fato do conhecimento dos espaços escolares.

Assim, neste capítulo compartilhamos as ações e experiências que o subprojeto Física vem, exitosamente, vivenciando desde agosto de 2018 nas cidades de Realeza/PR e Cerro Largo/RS e em suas imediações. Dentre as atividades desenvolvidas, destacamos que nosso trabalho está alinhado às premissas da Base Nacional Comum Curricular (BNCC) por meio da produção de materiais didáticos, do desenvolvimento de atividades práticas, do incentivo ao uso de recursos tecnológicos, do fomento a aprendizagem investigativa e autônoma e, também, promovendo formação continuada de professores das escolas e professores formadores da UFFS. Nesse contexto, cada núcleo conta com bolsas para três supervisores (professores das escolas), 24 discentes e um coordenador de área (professor do Curso de Física da UFFS), além de poder contar com professores colaboradores e de seis discentes voluntários. 


\section{CAMINHOS TEÓRICO-METODOLÓGICOS NOS PROCESSOS FORMATIVOS}

Dentre as muitas atividades de atuação propostas, destacamos a inserção dos licenciandos no cotidiano do ambiente escolar, que vem acontecendo de forma gradual, uma vez que os discentes do PIBID na configuração atual, como previsto pelo Edital n. 7/2018/Capes, é constituído de estudantes com até 60\% da carga horária do Curso de Física concluída, sendo que no núcleo de Realeza cerca de $50 \%$ dos discentes ainda estão no primeiro ano do curso, já no núcleo de Cerro Largo em torno de $30 \%$.

Nesse âmbito, para o subprojeto Física, núcleo de Realeza, a estratégia para a inserção dos licenciandos na escola foi de promover horários de permanência na escola e também de auxiliar os supervisores com orientações dos estudantes da escola para desenvolverem atividades experimentais sobre mecânica. Essas orientações ocorreram em pequenos grupos espalhados pela escola como quadra esportiva, pátio, áreas verdes como gramados e jardins, e outros ambientes informais de forma a favorecer o diálogo. Para o pibidiano, esse era o primeiro contato com os estudantes da escola na condição de um licenciando e o fato de não haver um roteiro pré-determinado lhe trouxe maior liberdade e autonomia. Depois de algumas orientações desses grupos pelos pibidianos, os estudantes da escola elaboraram os experimentos e os apresentaram para o professor, supervisor do PIBID.

Outra atividade que ocorreu paralelamente foi o estudo da realidade de escolas de sucesso, com a leitura e estudo do livro Viagem à Escola do Século XXI: assim trabalham os colégios mais inovadores do mundo (CALVO, 2016). Os estudos ocorreram semanalmente, quando cada pibidiano era responsável por conduzir o estudo na forma de um seminário dialogado, no qual os espectadores (estudantes, supervisores e coordenadores) eram incentivados a contribuir com seus comentários. Essa atividade 
tem como motivação o aperfeiçoamento da fala, da expressão, da postura e controle do tempo, da escrita na elaboração dos slides, assim como perder o medo de falar em público.

Os pibidianos são avaliados, pela coordenação do subprojeto, de uma forma didática e global, sem a atribuição de notas, de forma que ao apresentar um seminário o estudante não se sinta pressionado ou estressado, da mesma forma como ocorre em uma aula normal, na qual lhe é atribuído uma nota. Enquanto a leitura e o estudo do livro trazem ideias e sugestões de escolas bem-sucedidas e com modelos diferenciados, debate-se com os supervisores e pibidianos proximidades e possibilidades desses modelos à realidade das escolas da região.

Houve, também, uma atividade proposta para cada pibidiano foi a elaboração de um plano de aula abordando a Física e também temas interdisciplinares, para aplicação nas aulas de Física da escola. O plano de aula deve conter formas de resgatar os conhecimentos prévios dos estudantes e, na sequência, uma atividade prática envolvendo a utilização de recursos de tecnologias digitais, em alinhamento com as recomendações da BNCC. A escolha do tema, a metodologia e os procedimentos passam pela orientação da coordenação de área, colaboradora e supervisores e antes da execução da atividade na escola, que é realizada junto aos demais pibidianos, a fim de simular uma aula normal e detectar previamente possíveis ajustes.

$\mathrm{Na}$ Figura 1A, os pibidianos simulam uma atividade no campus da UFFS em Realeza. Nessa atividade cada pibidiano possui um cronômetro e ficam dispostos a cada 5 metros ao longo de uma linha reta, por onde um estudante irá iniciar e finalizar uma corrida. Os pibidianos medem, para cada intervalo de 5 metros, o tempo que o estudante leva para correr todo o trajeto. Com os dados obtidos, os estudantes constroem o gráfico da distância versus o tempo, como na Figura 1B, utilizando o software GeoGebra, disponível livremente na rede. Na sequência, são discutidas questões re- 
lacionadas à velocidade, velocidade média, aceleração, assim como questões relativas ao tempo de execução, adequabilidade, complexidade e sugestões que são analisadas entre todos do grupo.

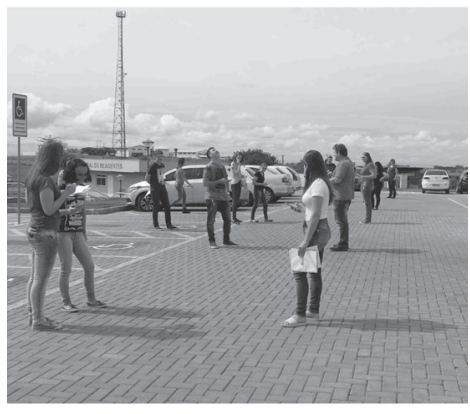

A

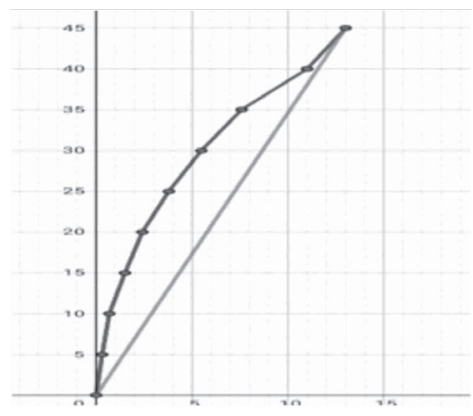

$\mathrm{B}$

Figura 1 - (A) estudantes do PIBID simula uma atividade para ser desenvolvida na escola (B) Gráfico do deslocamento versus o tempo referente à atividade

Fonte: Arquivo do PIBID Física

Já, quanto o núcleo de Cerro Largo do subprojeto Física, as atividades desenvolvidas permeiam o educar pela pesquisa (MORAES, 2004) e na investigação-formação-ação de forma dialógico-problematizadora de perspectiva freireana (FREIRE, 2001, 2005, 2009), nessa prática

[...] vão os educandos desenvolvendo o seu poder de captação e de compreensão do mundo que lhes aparece em suas relações com ele, não mais como uma realidade estática, mas como uma realidade em transformação, em processo. (FREIRE, 2005, p. 82).

Assim, consentindo a práxis - interação entre teoria e prática - como direcionadora do desenvolvimento das ações na busca 
da alfabetização científico-tecnológica dos estudantes, seguindo o referencial teórico da área de conhecimento específico (HALLIDAY; RESNICK; WALKER, 2012; HALLIDAY; RESNICK; WALKER, 2011a; HALLIDAY; RESNICK; WALKER, 2011b; HALLIDAY; RESNICK; WALKER, 2011c).

Nessa esfera, considerando o subprojeto proposto, há a realização de atividades em encontros semanais na universidade, entre as quais, seminários de livros (PORLÁN; MARTíN, 1997; FREIRE, 2005, ROMANOWSKI, 2007) (Figura 2C), participação em Programa Interdisciplinar de formação de professores, "Ciclos Formativos em Ensino de Ciências", seminário sobre experimentação. E, também, objetivando estudar e implementar intervenções e estratégias pedagógicas inovadoras e formativas que propiciem a significação e a apropriação dos conteúdos escolares realizamos o seminário de discussão da Base Nacional Comum Curricular (BNCC) (BRASIL, 2018).

Nas ações nas escolas, objetivando fortalecer a integração com a universidade como modo de qualificar tanto o ensino de Física como a formação do licenciando, os pibidianos têm desenvolvido, com o acompanhamento e orientação das professoras supervisoras e professora coordenadora, desde o reconhecimento e ambientação no espaço escolar como um todo, até atividades em sala de aula, tanto do Ensino Fundamental quanto do Ensino Médio com acompanhamento.

Dentre essas, podemos citar, por exemplo, as atividades relacionadas à Olimpíada Brasileira de Astronomia e Astronáutica ${ }^{5}$ (OBA), um evento anual que está na sua $22^{\mathrm{a}}$ edição, realizada em nível nacional, aberta a todas as escolas públicas e privadas e as atividades da Olimpíada ocorrem dentro da própria escola, essa podendo participar com qualquer número de estudantes e com todos os níveis de escolaridade da Educação Básica. Em diferen-

${ }^{5}$ Disponível em: http://www.oba.org.br/site/ 
tes escolas, os pibidianos realizaram atividades de retomada de tópicos de astronomia e realização de simulados, também, maquetes do sistema solar para a melhor visualização, avaliando e explicando questões específicas e de proporção e escala, explicando a impossibilidade de fazer a maquete atendendo a escala real entre os corpos celestes.

E, entendendo a importância do lúdico para a produção de conhecimento pelos estudantes, no intuito de discutir e compreender o nível de conhecimento desses sobre conceitos estruturantes de Física com a realização de jogos didáticos (LOPES, 2011; GURGEL; WATANABE; PIETROCOLA, 2017) (Figura 2D). Também, os pibidianos auxiliam os licenciandos estagiários na realização de práticas experimentais em sala de aula e no laboratório escolar, como sobre mecânica, movimento uniforme, para o primeiro ano do Ensino Médio, eletromagnetismo para o terceiro ano e cinemática, para o nono ano do Ensino Fundamental.

Também, houve a realização de práticas educativas experimentais nos laboratórios da UFFS, como as promovidas pelos núcleos de PIBID, Residência Pedagógica e PET Ciências do Campus para receber estudantes das escolas do entorno da UFFS, com as oficinas "O eletromagnetismo no cotidiano" e "A física por trás dos hand spinners", ilustradas na Figura 2B e 2A, respectivamente.

Para as atividades, seguimos metodologicamente de acordo com os três momentos pedagógicos (DELIZOICOV; ANGOTTI; PERNAMBUCO, 2002): problematização inicial: momento em que são apresentadas situações reais que tenham relação com o tema estudado, para verificarmos o nível de conhecimento dos estudantes; organização do conhecimento: instante em que são estudados os conhecimentos científico-tecnológicos necessários ao entendimento do tema sob a orientação do professor; aplicação do conhecimento: são retomados os conhecimentos estudados/discutidos, tanto os abordados na problematização inicial 
quanto situações novas que necessitem dos conhecimentos estudados, para avaliarmos se houve ganhos cognitivos com as situações propostas.

E, para a melhor compreensão dessas ações sobre o fazer docente, num movimento de (re)constituição do professor (estando ele em formação inicial ou continuada), fomentamos a escrita reflexiva do Diário de Bordo (PORLÁN; MARTÍN, 1997) pelas supervisoras, licenciandos e coordenadora, retratando as vivências, as práticas e os diálogos problematizadores formativos e a socialização dessas escritas entre os pares e na publicização de relatos de experiências em periódico da área.

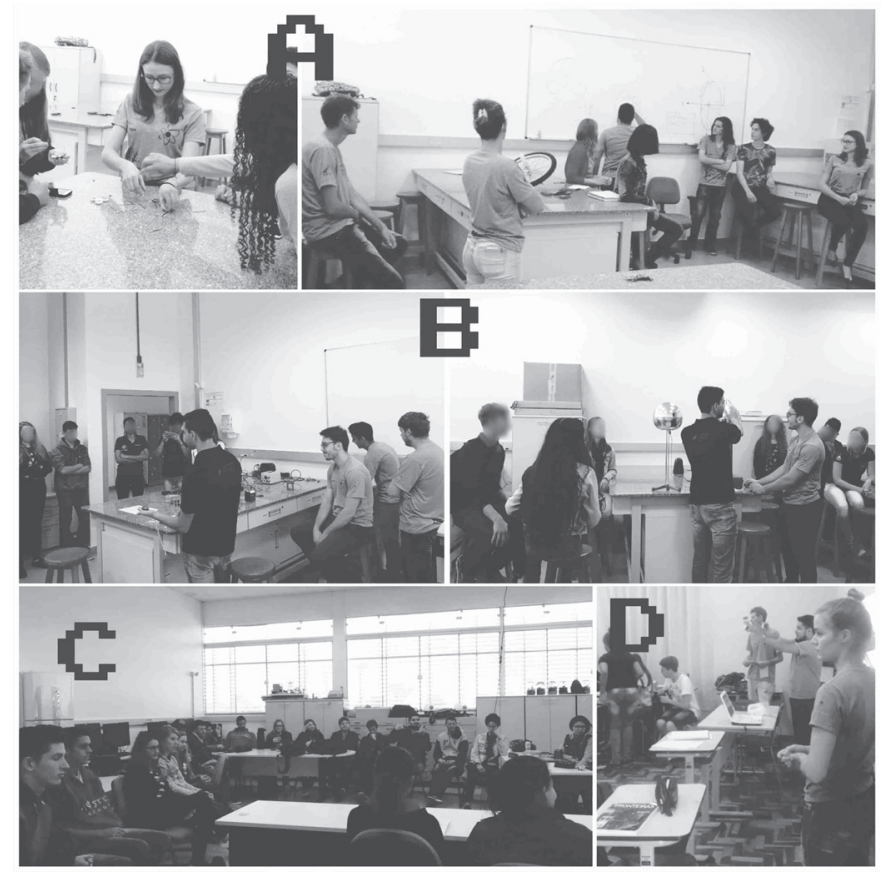

Figura 2 - (A), (B) Atividades nos laboratórios da UFFS, (C) Seminário do livro, (D) Atividade lúdica na escola Fonte: Arquivo do PIBID Física 


\section{AS VIVÊNCIAS FORMATIVAS}

É comum o relato de professores de Física sobre a falta de interesse dos estudantes para o desenvolvimento das tarefas de Física (CLEMENT, 2013). No contexto da teoria da autodeterminação, desenvolvida inicialmente por Deci e Ryan (1985), estudos mostram que há uma diminuição da motivação para aprender quando esses estudantes chegam à adolescência (PAIVA et al., 2018). A teoria da autodeterminação

[...] prevê a existência de diferentes orientações motivacionais e busca compreender como as mesmas se relacionam com o desempenho acadêmico dos estudantes e com as demais variáveis cognitivas, afetivas e sociais [...] (PAIVA et al., 2018, p. 1).

A motivação e a qualidade da motivação são fatores relevantes para aumentar o interesse dos estudantes e assim alcançar uma aprendizagem mais autônoma e crítico-reflexiva.

Desse modo, ponderando essa situação, a organização das atividades do Subprojeto se dá por meio da mediação, da investigação, da reflexão no âmbito do contexto escolar e acadêmico, buscando o desenvolvimento individual, social e profissional dos licenciandos. Desenvolvendo práticas educativas por meio de diferentes estratégias pedagógicas que possibilitam uma abordagem de ensino mais investigativa, com uso dos diferentes instrumentos culturais da pesquisa, como: textos literários, textos de divulgação científica, produção de histórias em quadrinhos, roteiros, filmes, jogos, experimentação, folders, softwares de animação, Tecnologias de Informação e Comunicação (TICs), debates, entre outros.

Buscando a reflexão pedagógica sobre o ensinar e aprender, sobre práticas educativas, contextualização, educar pela pesquisa e outras temáticas relacionadas com a realidade escolar vivencia- 
da qualificando a compreensão dessas práticas pedagógicas, na (re)significação da vivência escolar e na reflexão na e sobre a profissão docente. As leituras, as escritas e as intervenções na prática possibilitam uma (re)contextualização sobre o fazer docente e possibilitando ao licenciando ampliar a sua produção textual sob orientação do(a) coordenador(a) tendo em vista a formação qualificada de professor num movimento constante de pesquisa da própria prática (MORAES, 2004, FREIRE, 2005).

Nessa perspectiva, consideramos que PIBID oferece uma oportunidade de formação inicial de professores com uma riqueza muito grande, pois possibilita ao licenciando uma vivência na escola já a partir dos primeiros semestres do curso de graduação. $\mathrm{Na}$ escola, o pibidiano tem a chance de observar a rotina do ponto de vista de alguém que almeja tornar-se um professor, tomando consciência da realidade, observando como os professores lidam com a dinâmica da sala de aula e podem ter momentos de intervenção e interação com os estudantes da escola. Toda atividade na escola é acompanhada pelo professor supervisor, o que permite a ele um protagonismo na formação do licenciando.

Nas reuniões de grupo, discutimos metodologias de ensino inovadoras, preferencialmente as que motivem a participação do estudante, incentivando-os também ao uso das tecnologias digitais para favorecer o ensino-aprendizagem. Nos seminários, os pibidianos aperfeiçoam sua postura e expressão oral, desenvolvendo a autoconfiança e segurança ao perder o medo de falar em público.

Com toda essa experiência o pibidiano chegará ao estágio curricular supervisionado do curso muito mais preparado e confiante, como já vem ocorrendo com ex-pibidianos de projetos anteriores, assim como futuros professores mais conscientes das possíveis mudanças necessárias na atual metodologia de ensino presente nas escolas, problematizando conceitualmente, buscando aguçar a curiosidade epistemológica dos estudantes. 
Que vai ao encontro do exposto na BNCC, a qual traz como base a preocupação com a permanência dos estudantes no Ensino Médio, assim como a atual "[...] abordagem pedagógica distante das culturas juvenis e do mundo do trabalho." (BRASIL, 2018). Fato também explicitado nas Diretrizes Curriculares Nacionais (DCN):

Com a perspectiva de um imenso contingente de adolescentes, jovens e adultos que se diferenciam por condições de existência e perspectivas de futuro desiguais, é que o Ensino Médio deve trabalhar. Está em jogo a recriação da escola que, embora não possa por si só resolver as desigualdades sociais, pode ampliar as condições de inclusão social, ao possibilitar o acesso à ciência, à tecnologia, à cultura e ao trabalho. (BRASIL, 2011, p.167 apud BRASIL, 2018, p. 462).

As escolas, conjuntamente com o sistema de ensino, necessitam construir o currículo e uma proposta pedagógica de forma a respeitar as características, cultura e demandas locais, a fim de colaborar com os anseios dos estudantes. Para tanto, a BNCC sugere a flexibilização da organização curricular, asseguradas as competências e habilidades definidas para o Ensino Médio. Como estratégia, sugere a inclusão de atividades mais colaborativas, como aulas experimentais em laboratórios, observatórios e oficinas didáticas, de forma a fortalecer a autonomia e a criatividade dos estudantes, permitindo a esses uma verdadeira leitura de mundo, leitura consciente da realidade vivida.

E, na BNCC, a Física aparece contemplada na área de ciências da natureza e suas tecnologias, cujas atividades experimentais aparecem claramente na competência específica 3, a qual define "Analisar situações-problema e avaliar aplicações do conhecimento científico e tecnológico e suas implicações no mundo [...]" (BRASIL, 2018, p. 544). Para cada competência são definidas as 
respectivas habilidades a serem desenvolvidas pelo estudante e, de acordo com essa competência, uma das habilidades é

Construir questões, elaborar hipóteses, previsões e estimativas, empregar instrumentos de medição e representar e interpretar modelos explicativos, dados e/ou resultados experimentais para construir, avaliar e justificar conclusões no enfrentamento de situações-problema sob uma perspectiva científica. (BRASIL, 2018, p. 545).

As atividades experimentais são elementos motivadores para as aulas de Física, mas precisam ser pensadas e planejadas para que não seja simplesmente um roteiro a seguir ou um valor a ser encontrado. Elas possuem relevância no processo de aprendizagem e devem atender "[...] às expectativas dos estudantes e aos contextos sociais, numa postura problematizadora, investigativa." (AZEVEDO et al., 2009, p. 3).

Nesse prenúncio, as atividades experimentais, desenvolvidas pelos pibidianos conjuntamente com os estudantes da escola e supervisores, têm como preceito a postura investigativa, de forma a fomentar a iniciativa e a autonomia dos estudantes como formas de resolver problemas. As atividades em grupo promovem o diálogo e a confrontação de ideias, viabilizando a participação ativa dos estudantes na aprendizagem, motivando-os e incitando-os a relacionar a teoria à prática, práxis, normalmente desconectada na realidade escolar.

Também, não desconsiderando que o PIBID é um Programa de iniciação à docência, entretanto a formação proporcionada por ele não ocorre só para o professor em formação inicial, mas, igualmente, para o professor em formação continuada, seja ele o professor supervisor, o professor da escola ou o professor coordenador de área, o professor formador da universidade. Pois,

[...] qualquer tentativa de por em prática uma educação que, primeiro, respeitando a compreensão do mundo dos 
educandos os desafie a pensar criticamente; segundo, que não separe o ensino do conteúdo do ensino do pensar certo, exige a formação permanente dos educadores [...] (FREIRE, 2009, p. 168).

\section{CONSIDERAÇÕES FINAIS}

Considerando que "o ato de ensinar e de aprender, dimensões do processo maior - o de conhecer - fazem parte da prática educativa. Não há educação sem ensino, sistemático ou não, de certo conteúdo [...]" (FREIRE, 2009, p. 110), buscamos, com atividades de diversas perspectivas realizadas pelo subprojeto Física significar a formação de nossos professores em formação inicial bem como qualificar o ensino de Física desenvolvido por eles, na perspectiva de procurar responder as questões postas no início desse capítulo.

Primamos por uma educação criticizada, desenvolvida a partir do diálogo, da problematização com os estudantes com o intuito de romper com a cultura do silêncio e da passividade, muitas vezes presente e de torná-los epistemologicamente curiosos. E, como refere Freire $(2005,2009)$, essa dialogicidade não nega a validade de momentos de explicação, de narração, de exposição em que o professor fala do objeto, ela se propõe endagadora. Pois, esse diálogo não é um diálogo qualquer, ele inicia com a busca do conteúdo programático da educação, com a problematização da realidade vivida pelos estudantes para o entendimento dos fenômenos físicos, levando em consideração o contexto vivencial em que os estudantes estão inseridos.

Assim, estar encharcado de realidade contribui com mais êxito na formação do sujeito, professor em formação inicial, para sua iniciação à docência na qual compreende a necessidade de aprimoramento das dinâmicas de produção de conhecimento, 
das práticas educativas em sala de aula, da configuração curricular e colaborando para uma melhor valorização do educador da Educação Básica.

\section{REFERÊNCIAS}

AZEVEDO, Hernani Luiz et al. Uso do Experimento no Ensino de Física: tendências a partir do levantamento dos artigos em periódicos da área no Brasil. In: ENCONTRO NACIONAL DE PESQUISA EM EDUCAÇÃO EM CIÊNCIAS, VII, 7., 201, Florianópolis. Atas [...] Rio de Janeiro: ABRAPEC, 2009. p. 1-12.

BRASIL. Base Nacional Comum Curricular (BNCC).

Educação é a Base - Ensino Médio. 2018. Disponível em: http:// basenacionalcomum.mec.gov.br/wp-content/uploads/2018/02/bncc20dez-site.pdf. Acesso em: 2 maio 2019.

CALVO, Alfredo Hernando. Viagem à escola do século XXI: assim trabalham os colégios mais inovadores do mundo. São Paulo: Fundação Telefônica Vivo, 2016.

CLEMENT, Luiz. Autodeterminação e Ensino por Investigação: construindo elementos para promoção da autonomia em aulas de física. 2013. 334 f. Tese (Doutorado em Educação Científica e Tecnológica) - Programa de Pós-Graduação em Educação Científica e Tecnológica. Universidade Federal de Santa Catarina, Florianópolis, 2013.

DECI, Edward L.; RYAN, Richard M. Intrinsic motivation and selfdetermination in human behavior. New York: Plenum Press, 1985.

DELIZOICOV, Demétrio; ANGOTTI, José André P.; PERNAMBUCO, Marta Maria C. A. Ensino de Ciências: fundamentos e métodos. São Paulo: Cortez, 2002.

FREIRE, Paulo. Extensão ou comunicação? 12. ed. Rio de Janeiro: Paz e Terra, 2002. 
FREIRE, Paulo. Pedagogia da esperança: um reencontro com a pedagogia do oprimido. 16. ed. Rio de Janeiro: Paz e Terra, 2009.

FREIRE, Paulo. Pedagogia do oprimido. 48. ed. Rio de Janeiro: Paz e Terra, 2005.

GURGEL, Ivã; WATANABE, Graciella; PIETROCOLA, Maurício (org.). A elaboração de narrativas em aulas de Física: a aprendizagem em ciências como manifestação cultural. São Paulo: Livraria da Física, 2017.

HALLIDAY, David; RESNICK, Robert; WALKER, Jearl. Fundamentos de Física: mecânica, vol. 1, 9. ed. Rio de Janeiro: LTC, 2012.

HALLIDAY, David; RESNICK, Robert; WALKER, Jearl. Fundamentos de Física 2: gravitação, ondas e termodinâmica, vol. 2, 8. ed. Rio de Janeiro: LTC, 2011a.

HALLIDAY, David; RESNICK, Robert; WALKER, Jearl. Fundamentos de Física 3: eletromagnetismo, vol. 3, 8. ed. Rio de Janeiro: LTC, $2011 \mathrm{~b}$.

HALLIDAY, David; RESNICK, Robert; WALKER, Jearl. Fundamentos de Física 4: ótica e física moderna, vol. 4, 8. ed., Rio de Janeiro: LTC, 2011c.

LOPES, Maria da Glória. Jogos na educação: criar, fazer e jogar. 7. ed. São Paulo: Cortez, 2011.

MORAES, Roque. Educar pela pesquisa: exercício de aprender a aprender. In: MORAES, Roque; LIMA, Valderez Marina do Rosário (org.). Pesquisa em sala de aula: tendências para a educação em novos tempos. 2. ed. Porto Alegre: EDIPUCRS, 2004. p. 127-142.

NARDI, Roberto; CORTELA, Beatriz S. C. Formação inicial de professores de Física: novas diretrizes, antigas contradições. In: NARDI, Roberto; CORTELA, Beatriz Salemme Corrêa (org.). Formação inicial de professores de Física em universidades públicas: estudos realizados a partir de recentes reestruturações curriculares. São Paulo: Livraria da Física, 2015. p. 7-46. 
PAIVA, Fernando Fernandes et al. Orientações Motivacionais de Alunos do Ensino Médio para Física: considerações psicométricas. Revista Brasileira de Ensino de Física, São Paulo, v. 40, n. 3, p. e3.404, 2018.

PORLÁN, Rafael; MARTÍN, José. El diario del profesor: un recurso para la investigación en el aula. n. 6, 4. ed. Sevilla/ESP: Díada, 1997. (Colección Investigación y enseñanza).

ROMANOWSKI, Joana Paulin. Formação e profissionalização docente. 3 ed. Curitiba: Ibpex, 2007. 